\title{
Гусева A.X. \\ Дидактические аспекты организации научных исследований студентов-филологов и методика ведения практической работы
}

ФГБОУ ВО «Российский государственный гуманитарный университет»

(Россия, Москва)

doi: 10.18411/trnio-12-2021-267

\section{Аннотация}

Публикация посвящена методике организации и ведения научно-исследовательской работы студентов-филологов. Проанализировано понимание филологического исследования как вида профессиональной деятельности в контексте применения информационных технологий. Сформулированы основные дидактические положения ведения НИР. Рассмотрены виды учебной деятельности, выполняемые студентами в процессе работы над практической частью исследования.

Ключевые слова: научно-исследовательская работа, филологическое исследование, дисциплины гуманитарного цикла, профессиональные компетенции филолога, филологически значимая информация, анализ текста, литературный перевод.

\section{Abstract}

The publication is devoted to the methodology of organizing and conducting research work of students of philology. The understanding of philological research as a type of professional activity in the context of the use of information technologies is analyzed. The main didactic provisions for conducting research work are formulated. The types of educational activities performed by students in the process of working on the practical part of the research are considered.

Keywords: research work, philological research, disciplines of the humanitarian cycle, professional competence of a philologist, philologically significant information, text analysis, literary translation.

Научно-исследовательская работа студентов-филологов является разнообразной и аспектной и, как и любая многоэтапная научная деятельность, нуждается в корректной организации и мониторинге.

В узком смысле филология как наука представляет собой исследование совокупности различных стилей и жанров литературных текстов. Объектами исследования выступают художественные произведения, публицистические тексты, а также разнообразные тексты СМИ. Важно добавить, что с активной интеграцией в исследовательскую деятельность и образовательный процесс информационных технологий понимание научным сообществом филологии трансформировалось и обрело новые границы - сегодня это комплекс наук о культуре народа, нашедшей отражение в литературе в широком смысле слова.

В этой связи обучение студентов-филологов состоит не только в формировании и совершенствовании умений обработки текстов указанных типов на родном и иностранном языках, а, в первую очередь, приобретении знаний о культуре, истории и цивилизации родной страны и страны изучаемого языка. Преподаватель, ведущий дисциплины гуманитарного цикла, должен преподносить их как смежные науки, а оптимальная методика ведения аудиторных занятий направлена на ознакомление студентов с последующим пошаговым и поэтапным контролем с историческими фактами, культурными особенностями, некоторыми цивилизационными аспектами страны изучаемого языка с позиции филологических исследований.

Для студентов Института филологии и истории ФГБОУ ВО РГГУ процесс ведения исследовательской деятельности реализуется последовательно в формате рефератов (1-4 курсы, бакалавриат, 1-2 курсы, магистратура) курсовых проектов (2-3 курсы, бакалавриат, 1 
курс, магистратура) и выпускных квалификационных работ (4 курс, бакалавриат, 2 курс, магистратура).

Необходимо отметить, что на всех этапах организации НИР, подготовки к проведению исследования и его фактической реализации большое внимание уделяется отбору материала и изучению источников и литературы по теме. В данном контексте именно владение студентами цифровыми специализированными ресурсами имеет определяющее значение, а дисциплина «Информационные технологии в филологии» призвана сформировать профессиональные компетенции филолога, необходимые в профессиональной деятельности и ведении НИР.

Кратко охарактеризуем данную дисциплину, целью которой является ознакомление студентов со специальными программами, позволяющими находить корректную информацию в массивах данных, обрабатывать письменные тексты, материалы в аудио- и видео- форматах с целью получения лингвистически и филологически значимой информации и создания корпусов текстов, лексикографических баз данных и иной филологически значимой продукции. Среди задач назовем основные: 1. ознакомить с современными программными средствами хранения и обработки письменных, устных и мультимодальных текстов, а также создания и использования электронных корпусов; 2. овладеть технологиями обработки лингвистической и паралингвистической информации (электронными корпусами текстов, конкордансами (типа РНК (Ruscorpora) http://www.ruscorpora.ru/new/corporaabout.html, БНК (Natcorp), КРЛЯ (Narusco)), а также системами автоматического редактирования, лексикографическими базами данных и т.д.) (4, с.4-5).

Также следует перечислить компетенции, на формирование и совершенствование которых направлено освоение программы дисциплины, а именно: ОПК-6 (способность решать стандартные задачи профессиональной деятельности на основе информационной и библиографической культуры с применением информационно-коммуникационных технологий и с учетом основных требований информационной безопасности) и ПК-3 (владение навыками подготовки научных обзоров, аннотаций, составления рефератов и библиографий по тематике проводимых исследований, приемами библиографического описания; знание основных библиографических источников и поисковых систем) $(4$, с.6).

Далее конкретизируем понятие филологического исследования в контексте дисциплины «Информационные технологии в филологии».

Основными характерными отличиями ФИ является неразрывная связь с текстом, который может выступать как предметом, так и объектом его в зависимости от темы, в связи с тем, что текст не только продукт культуры, но и ее неотъемлемая часть и база. Согласимся с известным филологом Г.О. Винокуром, сформулировавшим задачу исследователя: «всякий языковед, изучающий язык, непременно становится исследователем той культуры, к продуктам которой принадлежит избранный им язык» (3, с.203).

При проведении данного вида НИР следует учитывать многоаспектность и корректно распределять этапы по времени, поскольку ФИ включает «следующие виды анализа: литературоведческий, биографический, исторический, композиционный, лингвистический, стилистический, риторический и другие» $(1$, с.38).

На вводном занятии проводится разъяснение задач ФИ студентам: 1. объяснить название; 2. понять композицию; 3. сформулировать художественный мир данного произведения (есть ли в нем сюжет; что является главным: события или переживания главного героя); 4. пояснить, как в произведении представлены пространство и время; 5. осознать особенности словоупотребления, синтаксиса, а также звучания.

На семинарских занятиях и индивидуальных консультациях студенты рассматривают текст как «промежуточное образование между действительностью и сознанием человека, всегда индивидуальную форму видения мира» $(1$, c.49). Одной из задач является перевод фрагмента выбранного произведения. Добавим, что при отработанной методике перевода специалист гуманитарного профиля способен воссоздать оригинал на иностранном языке, поскольку наиболее корректное понимание семантики, стиля и языковых средств текста 
оригинала присуща в большей степени не профессиональному переводчику, а самому автору.

Интересным является тот факт, что современные студенты-филологи все чаще стали обращаться к публицистике и текстам СМИ. Соответственно, НИР по филологии затрагивает такой сегмент, как медиатексты.

Далее рассмотрим методику проведения ФИ, объектом которого является медиатекст.

Современные медиатексты следует определить как «интегрирующие в едином смысловом пространстве разнородные компоненты (вербальные, визуальные, аудитивные, аудиовизуальные и другие») (5, с.36). Специалист, выполняющий перевод МТ, должен учитывать взаимосвязь и взаимозависимость формы и содержания МТ, придерживаться функционально-стилистических норм языка перевода, соблюдать принцип коммуникативной доминанты, применять прагматическую стратегию перевода с учетом того, что МТ определяется как «гипероним ряда предшествующих терминов: журналистский текст, PRтекст, публицистический текст, газетный текст, теле- и радиотекст, рекламный текст, текст интернет-СМИ» $(5$, с.36) и, в свою очередь, является элементом интегрального гипертекста.

Для грамотной работы по предлагаемой методике важно, чтобы текст оригинала был написан с учетом следующих параметров: «1. способ производства текста; 2. форма (фактура) медиатекста; 3. канал распространения; 4. функционально-жанровый тип текста; 5. тематическая доминанта» $(6, \mathrm{c.12})$. К примеру, студенты, создавая оригинал на родном языке, должны учитывать целевую аудиторию, формат текста (письменный, аудио- либо видео-), вычленить коммуникативную (прагматическую) задачу, а также составить предварительный глоссарий единиц, нуждающихся в переводческом комментарии. При переводе медиатекст может быть значительно изменен по форме, но главная цель состоит в том, чтобы полностью сохранить сюжет, придерживаться стилистических норм языка перевода, что позволит выполнить семантико-стилистически адекватный перевод МТ.

В соответствии с приведенными определениями медиатекст можно рассматривать как текст на иностранном языке, который студенты обрабатывают на практических занятиях с целью перевода корпуса текстов, объединенных конкретной тематикой, а также составления лексикографической базы данных и терминологического глоссария.

Практические задания выполняются студентами в соответствии с темой НИР на материале корпуса текстов выбранной тематики и способствуют решению следующих задач: 1. ознакомить со спецификой перевода источников гипертекстового формата на иностранном языке с помощью цифровых инструментов, а также особенностями переводческой деятельности в современных условиях; 2. выработать умение применять полученные знания в практической деятельности при переводе медиатекстов и аргументировано обосновывать собственные переводческие решения; 3. научить определять степень и уровень эквивалентности перевода медиатекста при его сопоставлении с оригиналом в процессе чтения с помощью современных программных средств; 4. научить проводить литературоведческий и лингвостилистический анализ посредством аудирования (визуализации), анализировать структуру медиаматериалов и выявлять подлежащее передаче содержание на базе технологий ТМ; 5. совершенствовать навыки работы на персональном компьютере и в сетевых средах с использованием текстовых редакторов, электронных энциклопедий, лексикографических баз данных, специализированного лингвистического и программного обеспечения переводчика.

Далее приведем основные положения методики ФИ при переводе и трансформации. Перечислим этапы работы и интерактивные задания: 1. ознакомление с источниками и классификация иноязычных медиатекстов; 2. выбор тематики МТ (МТ-12) для формирования корпуса медиатекстов; 3. выбор медиатекста (МТ-1) для лингвистической обработки с целью перевода в процессе чтения (аудирования, визуализации); 4. аналитическое чтение (аудирование, визуализация) оригинала; 5. поисковое и выборочное чтение (аудирование, визуализация) для создания терминологического глоссария; 6. структурирование медиатекста для перевода по ЛЕ, ГЕ, СЕ и СФЕ; 7. перевод текстов 
конкретного корпуса (МТ-1-12); 8. создание гипертекста МТ-12; 9. автоперевод МТ; 10. редактирование МТ.

В результате применения различных видов обработки медиатекстов данного корпуса студенты вырабатывают стратегию проведения ФИ с учетом предметных, языковых, социокультурных и дискурсивных знаний.

В заключение следует отметить, что в процессе применения данной методики организации и ведения НИР в области филологии формируются навыки работы с применением технологии интерредактирования, студенты совершенствуют профессиональные компетенции, необходимые для эффективной и корректной научной и переводческой деятельности с учетом производственной необходимости использования ИКТ в современных условиях, а также приобретают устойчивые навыки перевода и редактирования иноязычных СМИ.

$$
* * *
$$

1. Болотнова Н.С. Филологический анализ текста: учеб. пособие. 5е изд. М.: Флинта, 2016. 520 с.

2. Бразговская Е.Е. Текст культуры: от события к событию (логико-семиотический анализ механизма межтекстовых взаимодействий). Пермь: Перм. гос. пед. ун-т, 2004. 284 с.

3. Винокур Г.О. Филологические исследования. Лингвистика и поэтика. М.: Наука, 1990. 452 с.

4. Гусева А. Х. Информационные технологии в филологии. Направление подготовки 45.03.01 Филология. М: РГГУ, 2020. 52 с. [Электронный ресурс] URL:https://portal.rggu.ru/staff/methodics/ (дата обращения: 02.11.2021).

5. Кузьмина Н.А. Современный медиатекст: учеб. пособие. 3-е изд., стер. М.: ФЛИНТА, 2014. 416 с.

6. Солганик Г.Я. К определению понятий «текст» и «медиатекст» // Вестник МГУ. Серия 10. Журналистика. 2005. № 2. С. 7-15.

\section{Дзахова В.Т., Кайтукова С.И. \\ Основные цветообозначения в осетинском языке}

Северо-Осетинский государственный университет имени К.Л.Хетагурова

(Россия, Владикавказ)

doi: 10.18411/trnio-12-2021-268

\section{Аннотация}

В статье на основании критериев определения основных цветообозначений, сформулированных Б. Берлином и П. Кейом, анализируются цветообозначения осетинского языка. Привлекая к анализу данные этимологического словаря, а также частотность употребления, делается вывод о наличии в современном осетинском языке четырех основных цветообозначения.

Ключевые слова: осетинский язык, цветообозначения, базовые цветолексемы, эволюция цветонаименований.

\section{Abstract}

The article analyzes the color designations of the Ossetian language on the basis of the criteria for determining the main color designations formulated by B. Berlin and P. Kay. As a result of the analysis, it is concluded that there are four basic color designations in the modern Ossetian language.

Keywords: Ossetian language, color designations, basic color lexemes, evolution of color names.

Человек способен различать большое количество цветов. Однако названий для этих цветов в разных языках значительно меньше. Означает ли это, что люди, в чьих языках больше цветообозначений, лучше различают цвета? И следующий вопрос: что лежит в основе цветообозначений - нейрофизиология или культура? 